\title{
Mujeres en Salustio: estudio prosopo-historiográfico
}

\author{
Juan Luis PosAdAS \\ Universidad Antonio de Nebrija \\ jposadas@nebrija.es
}

\section{RESUMEN}

El historiador debe estudiar el corpus total de mujeres mencionadas en un autor antiguo para poder establecer una conclusión o un juicio sobre el mismo. Solo trabajando de este modo podemos llegar a entender el papel de las mujeres en la historia de Salustio: las romanas son denigradas como impúdicas y adúlteras, las extranjeras son alabadas como valientes y virtuosas. A pesar de esta conclusión, podemos añadir que Salustio es un buen autor para estudiar la actuación de algunas de las mujeres de finales de la república romana, si hacemos caso omiso de su presentación de las mismas.

Palabras clave: Historiografía romana, Salustio, mujeres, Sempronia, Fulvia, Aurelia Orestilla, extranjeras.

\section{Women in Sallust: a prosopographic and historiographical study}

\begin{abstract}
The historian must study all the women mentioned in an ancient author to make a statement or a judgement about him. Only working in that way, we can understand the role of women in the Sallustian history: the roman women are denigrated as immodest and adulteress, the foreigner are praised as brave and virtuous. Despite the fact of this, we can conclude that Sallust is a good author in order to study the actuation of some women in the final years of the Roman republic, just if we ignore some aspects of his narration.
\end{abstract}

Key words: Roman historiography, Sallust, women, Sempronia, Fulvia, Aurelia Orestilla, foreigner.

Sumario: 1. Introducción, 2. Mujeres identificadas, 3. Mujeres anónimas, 4. Conclusiones. 


\section{Introducción}

Tanto en mi Tesina como en mi Tesis doctoral, fechadas a comienzos de los años 1990, defendí el método prosopográfico como forma de acercamiento al análisis historiográfico sobre las mujeres romanas o extranjeras ${ }^{1}$. La idea era que el estudio de las mujeres mencionadas por tal o cual autor, o por un grupo de autores, no podía aislarse del conjunto de menciones a mujeres en sus obras: es decir, no se puede colegir la situación real de las mujeres romanas a partir de tres o cuatro ejemplos aislados, ni tan siquiera la opinión historiográfica de un autor usando solo dos o tres ejemplos entresacados de los muchos que pueden aparecer en sus obras.

Como ya he opinado en varias publicaciones sobre autores como Marcial, Juvenal, Plinio el Joven, Tácito, Suetonio o Floro ${ }^{2}$, al abordar el estudio de un tema tan controvertido como el de la situación de las mujeres en Roma, es preciso analizar previamente las fuentes literarias para discernir en qué sentido mencionan esas fuentes a las mujeres, con el fin de hallar sus posibles intencionalidades políticas, morales o retóricas, y así separar el grano de los hechos de la paja de las tergiversaciones historiográficas.

En los estudios mencionados he defendido que historiadores como Tácito, Suetonio o Floro usaron las menciones a mujeres como referentes de sus discursos (respectivamente) político, moral o retórico, más que nada para apoyar sus respectivos relatos historiográficos. En autores de otros géneros literarios, como los poetas Marcial y Juvenal o el epistológrafo y panegirista Plinio el Joven, he podido observar un tratamiento de las mujeres más apegado a la realidad, sin obviar tampoco la utilización de las mismas en sus discursos morales o políticos. He podido llegar a estas conclusiones estudiando el corpus total de menciones a mujeres identificadas por su nombre o por su vinculación parental a personajes conocidos (hija de Aufidio, esposa de Vario...), así como el resto de menciones a mujeres anónimas o a temáticas feme-

1 J. L. Posadas, Mujeres en Tácito: una aproximación prosopográfica, inédita (1991); ID., Retratos y caracteres femeninos en la literatura latina (época de Trajano), inédita (1994). Ambos trabajos fueron dirigidos por el prof. Gonzalo Bravo, catedrático de Historia Antigua de la Universidad Complutense. Sobre la prosopografía en los estudios historiográficos, véase a L. STONE, «Prosopografía», en El pasado y el presente, México, 1981, pp. 61-94; G. LEVI, «Les usages de la biographie», Annales ESC 1989, pp. 1317-1324; W. DE BOER, «Die prosopographische Methode in der Modernen Historiographie der hohen Kaiserzeit», Mnemosyne 22, 1969, pp. 268-280. En cuanto al mundo romano, véase a C. NicoleT, «Prosopographie et histoire sociale: Rome et l'Italie à l'époque républicaine», Annales ESC 1970, pp. 1209-1228; y a A. ChASTAGNol, «La prosopographie, méthode de recherche sur l'histoire du Bas-Empire», Annales ESC 1970, pp. 1229-1235.

2 J. L. Posadas, «Extranjeras en la Roma de Marcial y Juvenal», SHHA 28, 2010, pp. 73-92; ID., «Clientelas y amistades femeninas en Plinio el Joven», SHHA 26, 2008, pp. 87-105; ID., «Extranjeras en la historiografía romana del siglo II d. C.», en G. Bravo Castañeda-R. González Salinero (Eds.), Extranjeras en el mundo romano, Madrid, Anejo VIII Gerión, 2004, pp. 67-80; ID., «Las mujeres en la historiografía tacitea», en Actas del VIII Congreso Español de Estudios Clásicos, Madrid, vol. III, 1994, pp. 541-546; ID., «Mujeres en Tácito: retratos individuales y caracterización genérica», Gerión 10, 1992, pp. 145-154. A estos estudios hay que sumar el recientemente publicado «Las mujeres en la narración y la acción de César, los cesarianos y Salustio», SHHA 29, 2011, pp. 251-276, en el que estudié todas las menciones a mujeres en las obras de Julio César, del corpus cesariano y también adelanté las conclusiones de mi estudio sobre Salustio. Escribo "adelanté" porque dicho artículo fue redactado en verano de 2011, varios meses después de haber terminado este artículo de Gerión, enviado a la revista en enero de 2011. 
ninas. Tras reunir dichos corpora, realicé un análisis cuantitativo de las menciones consideradas positivas, las negativas y las neutras, y puse en relación dicho análisis con los contextos y los posibles posicionamientos de los autores. Solo así, en mi opinión, se pueden colegir los motivos de dichas menciones y su validez como datos históricos o no.

En el caso de la historiografía, tras el estudio de autores como Tácito, Floro o Suetonio, parece lógico iniciar un estudio de algunos de los autores que precedieron a estos, desde la época republicana (los analistas, César y Salustio), a la augústea (Tito Livio), y a los autores del siglo I d.C. (Veleyo Patérculo y Valerio Máximo). Mi intención es comprobar si las menciones de estos autores van en la misma línea que los autores posteriores, por si de alguna manera estos imitaron a aquellos, o si la general tónica de las menciones puede indicar una realidad histórica o no.

Por afinidad estilística y por otras razones, he elegido como comienzo de esta serie de estudios a Gayo Salustio Crispo. Para este trabajo, cuestiones filológicas (y opinables) aparte, consideraré como obras salustianas la Conjuración de Catilina, la Guerra de Yugurta, las Historias, las dos Cartas a César anciano sobre asuntos de Estado, y la Invectiva contra Cicerón; aunque, de estas obras atribuídas, yo (modestamente) crea solo en la autenticidad de la primera $\mathrm{Carta}^{3}$. En todas estas obras aparecen 17 mujeres identificadas prosopográficamente, en un total de 23 menciones, y otras 22 menciones a mujeres anónimas de diversos tipos y orígenes.

\section{Mujeres identificadas}

En primer lugar, es interesante constatar que, de esas diecisiete mujeres identificadas, solo se citan por su nombre a seis (la tercera parte): Aurelia Orestila (esposa de Catilina), Fulvia (amante de Quinto Curio), Julia (madre de Mario), Nisa (reina de Bitinia), Sempronia (esposa de Junio Bruto), y Terencia (esposa de Cicerón). Se mencionan además a tres hijas de personajes conocidos (Tulia de Cicerón, Sergia de Aurelia Orestila y la hija del rey Boco de Mauritania), a dos concubinas reales númidas, a dos amantes (de Catilina), a una esposa (de Sila) y a una hermana (de Mitrídates). Junto con ellas, habría dos menciones dudosas, que los filólogos han atribuido a Precia (amante del tribuno Cetego), y a Clodia (hermana de P. Clodio Pulcro) ${ }^{4}$.

${ }^{3}$ He usado las siguientes traducciones: B. Segura Ramos, Salustio, Madrid, Biblioteca Clásica Gredos, 1997 (para la Conjuración de Catilina, Guerra de Yugurta y obras atribuídas), y J. L. Posadas, Gayo Salustio Crispo: Fragmentos de las Historias, Madrid, Ediciones Clásicas, 2006 (tanto la traducción como el texto en latín para esta obra fragmentaria). El texto en latín es, para todo lo que no son las Historias, de F. Pasoli, Opere di Caio Sallustio Crispo, Turín, 1991. Mi opinión sobre la primera carta está en el libro citado, pp. 15-16.

${ }^{4}$ Aurelia Orestila (Cat. 15.2, 35.3, 35.6), ¿Clodia? (Hist. 5.11), Fulvia (Cat. 23.3-4, 26.3, 28.2-3), Julia (Hist. 1.35), Nisa (Hist. 4.69.9), ¿Precia? (Hist. 3.18), Sempronia (Cat. 25.1-4, 40.5), Sergia (Cat. 35.3), Terencia (Inv. 2.1-3), Tulia (Inv. 2.1-3), amante noble de Catilina (Cat. 15.1), amante vestal de Catilina (Cat. 15.1), concubina abuela de Masúgrada (Jug. 108.1), concubina de Masinisa y madre de Mastanábal, padre de Yugurta (Jug. 5.7), hermana de Mitrídates (Hist. 2.76), hija de Boco de Mauritania (Jug. 80.6) y esposa de Sila (¿Julia Cornelia?) (Jug. 95.3). 
La primera impresión es que, para una obra abultada, aparecen muy pocas mujeres concretas, y menos identificadas por su nombre. La segunda es que la mayoría aparecen en la Conjuración de Catilina, una obra que, al transcurrir íntegramente en Roma y sus aledaños, por lógica habría de incluir a las esposas, amantes o hijas de los protagonistas de los hechos. De las tres principales mujeres de la historiografía salustiana (Aurelia Orestila, Fulvia y, sobre todo, Sempronia), solo la última ha merecido alguna atención de los estudiosos de Salustio y también de los estudiosos de eso que se ha dado en llamar "la mujer romana"s. Lógicamente también, la temática "extranjera" y bélica de la Guerra de Yugurta no se prestaba a la mención de muchas mujeres identificadas prosopográficamente, salvo algunas concubinas númidas o la esposa del propio Yugurta, hija a su vez del rey Boco. Y, por fin, el carácter fragmentario de las Historias, obra sometida en su vaivén filológico al interés arbitrario de sus escoliastas y transmisores, tampoco ha facilitado la supervivencia de demasiadas menciones femeninas.

En este primer grupo de mujeres identificadas sorprenden algunos "retratos" psicológicos y morales completos. En ellos se deslizan, sin duda, estereotipos sociales, morales y políticos. También las opiniones del autor y sus odios o inquinas. Pero es posible hallar también algunos rasgos históricos que podrían servirnos para el estudio de algunas de estas mujeres de época republicana. Los retratos más importantes son los de Sempronia, Fulvia y Aurelia Orestila. Vayamos con el primero:

«Ahora bien, entre estas se contaba Sempronia, que muchas veces había llevado a cabo actos propios de la osadía de un hombre. Esta mujer por su alcurnia y su belleza, y también por su marido y por sus hijos, era bastante afortunada; versada en la literatura griega y latina, tocaba la lira y bailaba con más elegancia de lo que una mujer honesta necesita, y poseía otras muchas cualidades que son instrumento de la disipación. Pero para ella todo era más estimable que la honra y la decencia; no era fácil dilucidar qué respetaba menos, si su dinero o su reputación; su pasión era tan encendida que cortejaba ella a los hombres con más frecuenca de lo que era cortejada. Antes había traicionado muchas veces su palabra, había negado con perjurio haber recibido un préstamo, había estado complicada en un crimen; su lujo y su falta de medios la habían llevado a la ruina. Ahora bien, poseía cualidades extraordinarias: sabía escribir versos, hacer chanzas, llevar una conversación ya seria, ya distendida o procaz; tenía, en fin, mucha sal y mucho encanto» (Cat. 25.1-4) .

5 Los principales trabajos sobre Sempronia son: B. W. BoyD, «Virtus effeminata and Sallust's Sempronia», TAPhA 117, 1987, pp. 183-201; T. CAdouX, «Sallust and Sempronia», en B. Marshall (Ed.), Vindex humanitatis. Essays in honour of John Huntly Bishop, Armidale, 1980, pp. 93-122; G. M. PAUL, «Sallust's Sempronia. The portrait of a lady», en F. Cairns (Ed.), Papers of the Liverpool Latin Seminar, Liverpool, vol. V, 1985, pp. 9-22; y A. IBÁÑEz CHACón, «Salustio y Sempronia: mujer y política en la antigua Roma», Cudas 7-8, 2006-2007, pp. 67-89.

${ }_{6}$ Sed in iis erat Sempronia, quae multa saepe uirilis audaciae facinora conmiserat. Haec mulier genere atque forma, praeterea uiro liberis satis fortunata fuit; litteris Graecis Latinis docta, psallere [et] saltare elegantius quam necesse est probae, multa alia, quae instrumenta luxuriae sunt. Sed ei cariora semper omnia quam decus atque pudicitia fuit; pecuniae an famae minus parceret, haud facile discerneres; lubido sic adcensa, ut saepius peteret uiros quam peteretur. Sed ea saepe antehac fidem prodiderat, creditum abiurauerat, caedis conscia fuerat: luxuria atque inopia praeceps abierat. Verum ingenium eius had absurdum: posse uersus facere, iocum mouere, sermone uti uel modesto uel molli uel procaci; prorsus multae facetiae multusque lepos inerat. 
La Sempronia de Salustio presenta luces y sombras: por un lado se enumeran todas las virtudes que, supuestamente, debían adornar a una mujer romana: nobleza, belleza, matrimonio e hijos, cultura en ambas lenguas, versada en música, poesía y danza, buena conversadora... Y por otro todos los vicios peor considerados en una mujer: disipada, indecente, impúdica, adúltera (y además llevando ella la iniciativa ${ }^{7}$ ), perjura, criminal, ostentosa en el lujo y arruinada. Este retrato complejo y ambiguo ha sido muy debatido: Sempronia ha sido calificada de fatale monstrum (como la Cleopatra de Horacio) por Boyd, quien piensa que Salustio "fabricó" un estereotipo de mujer ambiciosa metida en política, aunque con algunos rasgos históricos verdaderos; Cadoux abunda en esa opinión, incidiendo en la ambigüedad del relato salustiano y en la historicidad del personaje; Paul ha estudiado a los historiadores griegos del período y cree que Salustio, influenciado por ellos, mencionó a Sempronia como un personaje más de la historia trágica que estaba relatando; $y$, finalmente, Ibáñez vuelve a incidir en que la inquina y la crítica salustiana a Sempronia procede de su implicación en asuntos judiciales y políticos reservados exclusivamente a los hombres ${ }^{8}$.

Desde mi punto de vista, creo que Salustio utilizó una técnica historiográfica observable en otros historiadores como Tácito, consistente en colocar una virtud primero para luego manipularla con una crítica en segundo término: tocaba y bailaba/ más que una mujer honesta; muchas cualidades/para la disipación. En Tácito se ve que él introduce su opinión en el segundo término"; en Salustio podría ocurrir lo mismo ${ }^{10}$, por lo que podría ser un precedente para el propio Tácito. Aunque la lista de conceptos positivos es mayor que la de conceptos negativos, hay que tener en cuenta el contexto del párrafo: Salustio presenta a Sempronia como ejemplo de un grupo de mujeres "catilinarias" que, debido a sus deudas por razones sexuales, estaban prontas a secundar al conspirador para complicar o asesinar a sus maridos y soliviantar a sus esclavos:

«Se dice que por aquella época atrajo a sí a muchísimos hombres de todo tipo, y a algunas mujeres también, que primero habían sobrellevado enormes gastos con el comercio sexual y que luego, cuando la edad había puesto límite a las ganancias solo, y no a sus despilfarros, habían contraído grandes deudas. Catilina confiaba en que por

7 Esto era algo muy mal visto en la sociedad romana, según P. Veyne, Sexo y poder en Roma, Madrid, 2010, pág. 157.

8 Estos autores han sido citados en la nota 5 .

9 J. L. Posadas, «Mujeres en Tácito...», citado, pág. 154. Las técnicas de insinuación insidiosa de Tácito han sido estudiadas por I. S. RYBERG, «Tacitus' art of innuendo», TAPhA 73, 1942, pp. 383-404, esp. pág. 389; D. Sullivan, «Innuendo and the weighted alternative in Tacitus», CJ 71, 1976, pp. 312326, esp. pp. 317-318; y por R. Develin, «Tacitus and techniques of insidious suggestion», Antichton 17, 1983, pp. 64-95, esp. pág. 66.

${ }^{10}$ Cf. M. L. S. McConaghy, Sallust and the literary portrayal of character, Missouri, 1973, pp. 127-145. Desde luego, no estoy tan seguro de las conclusiones de B. RIPOSATI, «L'arte del ritratto in Sallustio», RCCM 10, 1968, pp. 168-189, quien piensa que Salustio fue un gran retratista de personajes, discerniendo lo bueno de lo malo en cada uno de ellos: fue, como todo buen historiador romano, un hábil manipulador en la descripción de los caracteres para que le sirvieran en sus propósitos historiográficos, morales o políticos. 
medio de ellas podría soliviantar a los esclavos de la ciudad, incendiar a esta y unir a él o asesinar a sus maridos» (Cat. 24.3-4) ${ }^{11}$.

Lógicamente, este contexto es muy negativo. Sin embargo, en la segunda y última cita de Sempronia (Cat. 40.5), el contexto es precisamente mostrar dónde (en su casa) se reunieron los alóbroges con Umbreno y Gabinio para denunciar a Catilina y a sus cómplices.

Por tanto, creo que en Sempronia hay un práctico "empate" entre conceptos negativos y positivos, si bien inclinándose la opinión de Salustio hacia los primeros, y también un "empate" entre el contexto negativo del retrato y el positivo de la segunda cita. Parece razonable suponer que Salustio intentó criticar a las mujeres que se complicaron en los enredos políticos del final de la República (más con invectivas morales sobre su impudicia o su disipación en el tren de vida que con críticas a sus posicionamientos políticos), sin ocultar que algunas de ellas hicieron inclinar la balanza hacia el bien y no hacia el mal. Las virtudes de Sempronia, entre ellas las muy valoradas de belleza, nobleza y fecundidad, parecen, en todo caso, sobrepasar numéricamente a sus vicios, por lo que, finalmente, Sempronia puede considerarse una mujer que supera el estándar moral del autor. Su historicidad como esposa de Décimo Junio Bruto y madre de Décimo Junio Albino ${ }^{12}$, personajes próximos a César, es bastante plausible, según los argumentos mostrados por autores como Duval ${ }^{13}$. Esta condición "cesariana" de Sempronia y de su marido los colocaba en la facción del propio Salustio, por lo que parece improbable que este autor criticara a la susodicha dama en su obra ${ }^{14}$. Sin embargo, Sir Ronald Syme sugirió en su día que el hecho de ser Sempronia madre o tía de Décimo Bruto, uno de los cesaricidas, le habría servido a Salustio para saldar cuentas con este a través de su pariente femenino ${ }^{15}$. Me parece más probable la otra explicación que da este autor a la presencia de Sempronia en el relato, habida cuenta su ínfima implicación en los acontecimientos: la necesidad salustiana de llenar espacio con una digresión moralista ${ }^{16}$.

El segundo retrato, aunque menos completo, es el de Fulvia:

«Mas en esta conjuración estuvo Quinto Curio, de origen no humilde, cubierto de infamias y crímenes, a quien los censores habían expulsado del Senado por disoluto.

${ }^{11}$ Ea tempestate plurumos quoiusque generis homines adsciuisse sibi dicitur, mulieres etiam aliquot, quae primo ingentis sumptus stupro corporis tolerauerant, post ubi aetas tantummodo quaestui neque luxuriae modum fecerat, aes alienum grande conflauerant. Per eas se Catilina credebat posse seruitia urbana sollicitare, urbem incendere, uiros earum uel adiungere sibi uel interficere.

12 Según C. Herrman, Le rôle judiciare et politique des femmes sous la République romaine, Bruselas, 1964, pág. 103.

${ }^{13}$ G. M. Duval, «D. Junius Brutus: mari ou fils de Sempronia?», Latomus 50, 1991, pp. 608-615.

14 J. L. PosadAs, «La integración de las mujeres en la política republicana: de Sempronia a Octavia», en G. Bravo Castañeda-R. González Salinero (Eds.), Formas de integración en el mundo romano, Madrid, Editorial Signifer, 2009, pp. 237-248, esp. pp. 239-240. Sobre el posicionamiento político de Salustio, primero en las filas de Craso, luego en las de César y, finalmente, en las de Marco Antonio, véase a J. L. Posadas, «Las Historias de Salustio: un documento antoniano», Arx. World Journal of Prehistoric and Ancient Studies 1, 1995, pp. 47-51.

15 R. Syme, Sallust, Berkeley, 1964, pp. 134-135.

16 ID., pág. 133. 
[...] Le importaba muy poco no callar lo que había oído ni ocultar sus propios crímenes, así como lo que decía o hacía. Este individuo mantenía con Fulvia, mujer de la alta sociedad, una antigua relación de adulterio. Comoquiera que fuese menos grato para ella porque, debido a la falta de medios, no podía hacerle regalos, de la noche a la mañana comenzó a alardear y a prometerle montes y mares, a amenazarle a veces con la espada si no seguía a sus órdenes, y por último a actuar con más violencia de la que acostumbraba. Pero he aquí que Fulvia, al conocer la razón de la insolencia de Curio, no mantuvo oculto semejante peligro para el Estado, sino que, excepto el nombre del informante, contó a muchos lo que había oído, y el modo como lo había oído, de la conjuración de Catilina» (Cat. 23.1-4) ${ }^{17}$.

Además de este texto, que contiene algunas trazas de retrato, en otros dos párrafos (Cat. 26.8 y 28.2-3), Salustio nos cuenta que esta Fulvia fue la principal informante de Cicerón sobre los planes de los conjurados, y que, gracias a ella, el propio cónsul se salvó de ser asesinado. Sobre Fulvia hay poco conocimiento, ya desde antiguo: según Salustio y Apiano, era mujer noble; y según Floro, una «prostituta despreciable, pero menos nociva que los patricios ${ }^{18}$. En esta mención se reitera lo ya visto en Sempronia: que en Salustio parece haber un crítica soterrada a las mujeres que participaban en política, ya que unió esa participación con supuestas conductas desviadas como el adulterio. Por supuesto, el hecho de que Fulvia fuera una actriz fundamental, tanto en el descubrimiento de la conjuración como en la evitación de la muerte del cónsul, salva a esta dama del ataque salustiano y proporciona una imagen positiva de la misma. A esto añadiré yo que, si R. Syme estaba en lo cierto $^{19}$, y Fulvia estaba emparentada con la Fulvia esposa de Marco Antonio, Salustio se cuidaría de criticar a la pariente del triunviro, habida cuenta la posible militancia del historiador en las filas de Marco Antonio (véase nota 14).

La tercera mujer identificada "retratada" por Salustio es Aurelia Orestila, segunda esposa del propio Catilina ${ }^{20}$. Esta Aurelia era la hija de Gn. Aufidio Orestes, cos. 71, $\mathrm{y}$, al parecer, viuda de un primer matrimonio con Q. Cecilio, a consecuencia del cual tenía una hija, Sergia ${ }^{21}$. El retrato que nos ofrece Salustio es bastante revelador, ya que, al tratarse de la mujer de Catilina, es de esperar que ese retrato sea negativo. Veámoslo:

17 Sed in ea coniuratione fuit $Q$. Curius, natus haud obscuro loco, flagitiis atque facinoribus coopertus, quem censores senatu probri gratia mouerant. [...] Neque reticere quae audierat, neque suamet ipse scelera occultare, prorsus neque dicere neque facere quicquam pensi habebat. Erat ei cum Fuluia, muliere nobili, stupri uetus consuetudo, quoi cum minus gratus esset, quia inopia minus largiri poterat, repente glorians maria montisque polliceri coepit et minari interdum ferro, ni sibi obnoxia foret, postremo ferocius agitare quam solitus erat. At Fuluia insolentia[e] Curi causa cognita tale periculum rei publicae haud occultum habuit, sed sublato auctore de Catilinae coniuratione quae quoque modo audierat compluribus narrauit.

18 App. BC 3.3.8; Floro 2.12.6. Traducción de G. Hinojo Andrés-I. Moreno Ferrero, Floro: Epítome de la Historia de Tito Livio, Madrid, Biblioteca Clásica Gredos, 2000. Sin embargo, C. Herrmann, Le rôle judiciare et politique..., citado, pág. 104, yerra al creer a esta Fulvia la misma que luego fue esposa de Clodio y de Marco Antonio.

19 R. Syme, Sallust, citado, pp. 135-136.

20 Había estado casado anteriormente con una tal Gratidia.

${ }^{21}$ App. BC 2.2, Cic. Cat. 114, Cic. Fam. 8.7.2. M. Lightman-B. Lightman, Ancient greek and roman women, Nueva York, 2000, pág. 38. 
«Finalmente, encaprichado del amor de Aurelia Orestila, de quien ninguna persona decente alabó nunca otra cosa a no ser su belleza, comoquiera que ella dudaba en casarse con él por temor a un hijo ya adulto que él tenía, se acepta como seguro que dio muerte a su hijo y dejó la casa libre para la criminal boda. Este hecho precisamente me parece a mí haber sido la causa primordial de acelerar su crimen» (Cat. 15.2-3) ${ }^{22}$.

A este retrato hay que sumar los pocos datos inferibles de una supuesta carta que mandó Catilina a Catulo despidiéndose de él y encomendándole a su mujer (Cat. 35.3-6). En esta carta, Catilina aduce que podría haberse librado de sus deudas con sus bienes o con los de su mujer, incluso con los de la hija de esta, y recomienda a Catulo que cuide de Orestila y la defienda de agravios. Si bien la presentación "dramática" de los últimos momentos de un romano encomendando a su viuda suele buscar un efecto positivo en los lectores, lo cierto es que esta Aurelia es presentada por Salustio no solo como desencadenante de la conjuración de su marido, sino como el motivo de que este asesinara a su propio hijo, lo cual le llevó a la locura. Otro dato interesante podría inferirse de la carta: que tanto Aurelia como su hija disponían de sus propios bienes, es decir, estaban emancipadas y sin tutor, algo no muy bien visto en la sociedad romana porque indicaba que las damas en cuestión eran libres para hacer con sus patrimonios y sus vidas lo que quisieran. En definitiva, Aurelia Orestila, mujer de la nobleza senatorial por ser hija de un excónsul, viuda y madre de una hija, independiente económicamente, según Salustio volvió "loco" a Catilina debido al mal uso que daba a su belleza, y provocó la muerte del hijo de su amante porque no quería contraer matrimonio con alguien que tuviera un heredero ${ }^{23}$; lo cual sería, a la postre, causa prima de la conjuración de Catilina.

Porque, como se va viendo con las tres mujeres presentadas, estas son parte importante del relato salustiano: son, o bien el origen de la conjuración (Aurelia), o bien parte integrante de la misma (Sempronia, aunque luego se desmarque), o bien la denunciante al cónsul (Fulvia). Como razón de este protagonismo femenino en la obra, solo hay un elemento común a todas ellas: su impudicia, su belleza usada con malos fines, su adulterio. Es decir, una razón moral para su actuación política (acertada o no).

Las otras mujeres identificadas (un total de catorce), con menciones muchísimo menos importantes, transmiten sensaciones parecidas. Son reseñables, entre todas ellas, la hija de Boco, casada con Yugurta, despreciada por este debido a la costumbre poligámica de los númidas (Jug. 80.6); la mujer de Sila, que aparece en un contexto en el que este es criticado por su "ansia de placeres", siendo su esposa víctima de la falta de rectitud del romano (Jug. 95.3); la mujer e hija de Cicerón, criticadas por sus sacrilegios, perjurios, y con sospechas de incesto (Inv. 2.1); Julia, la madre de

${ }^{22}$ Postremo captus amore Aureliae Orestillae, quoius praeter formam nihil umquam bonus laudauit, quod ea nubere illi dubitabat timens privignum adulta aetate, pro certo creditur necato filio uacuam domum scelestis nuptiis fecisse. Quae quidem res mihi in primis uidetur causa fuisse facinus maturandi.

${ }^{23}$ App. BC 2.2: «Gayo Catilina era un hombre preclaro, en razón de la importancia de su fama y la brillantez de su linaje, pero era un loco que parecía incluso que, en cierta ocasión, había matado a su propio hijo a causa de su amor por Aurelia Orestila, porque esta no aceptaba casarse con un hombre que tenía un hijo». Traducción de A. SÁnchez Royo, Apiano: Historia romana, vol. 2, Madrid, Biblioteca Clásica Gredos, 1985. 
Mario, que se opuso a su aspiración al consulado (Hist. 1.35); y ¿Precia?, la amante de Cetego, trib. pleb. 73, alabada o, más bien, criticada por su cultu corporis egregio (Hist. 3.18). Hay en ellas dos que provocan simpatía en el lector por haber sido despreciadas o maltratadas por sus maridos, pero en general son mujeres criticadas por sus supuestas malas artes, su "intromisión" en política, o por su belleza, cualidad que en Salustio (como en todo moralista cerrado) parece conducir a la perdición.

La conclusión general sobre las mujeres identificadas en Salustio, desde un punto de vista prosopo-historiográfico, es que estas son juzgadas con una óptica moralista, en función de la utilización de su belleza y supuestas artes "femeniles", sobre todo cuando, en el parecer de Salustio, se inmiscuían en política, bien con consejos dados a "sus hombres" (Julia, Aurelia), bien con su participación en las banderías políticas de la época, aun siendo esta participación para bien (Fulvia, Sempronia). Por supuesto, esta óptica moralista no impide que Salustio pueda o deba ser utilizado como fuente de conocimiento histórico sobre algunas de estas mujeres, si bien matizando sus comentarios e interpretaciones para despojarlas de la crítica, soterrada o no, a tales mujeres ${ }^{24}$.

\section{Mujeres anónimas}

Por supuesto, en un buen estudio prosopo-historiográfico, tales conclusiones sobre las mujeres identificadas han de contrastarse con el estudio de las múltiples menciones a mujeres anónimas, tanto individuales como colectivas: es decir, a todas las menciones a temática "femenina" en la obra del autor estudiado.

Las veintidós menciones a mujeres anónimas en las obras de Salustio pueden clasificarse, grosso modo, de la siguiente manera (por orden de importancia numérica):

- Mujeres romanas: Cat.31.3, 51.9; Ep. 1.4.2, 2.4.2; Jug. 85.40-41; Hist. 1.60, 1.77.19, 3.98.3.

- Rameras: Cat. 7.4, 11.6, 14.6; Ep. 1.4.4, 1.8.2.

- Mujeres númidas: Jug. 67.1, 80.6-7, 94.5.

- Mujeres hispanas: Hist. 2.91, 2.92.

- Adúlteras: Cat. 13.3, 24.3-4.

- Esclavas: Jug. 12.5.

- Mujeres galas: Hist. 4.40.

La importancia de las mujeres romanas sobre el resto de "orígenes" es aún mayor si tenemos en cuenta que casi todas las rameras y adúlteras son romanas. La única esclava que aparece es númida. Los contextos de estas menciones son la conjuración de Catilina (principalmente, pero no solo) para las romanas, la guerra de Yugurta para las númidas, la guerra de Sertorio para las hispanas, y la rebelión espartaquíada para las galas (estas dos últimas, como se ve, en las Historias). Antes de proceder a su estudio detallado, hay que volver a reiterar el hecho de que las Historias nos han

${ }^{24}$ Así lo he intentado en J. L. Posadas, Emperatrices y princesas de Roma, Madrid, 2008, pp. 26-30, en referencia a algunas damas de finales de la República. 
llegado de manera fragmentaria, por lo que ha sido el azar de la fortuna y transmisión del texto el que ha determinado qué menciones podemos analizar y cuáles no.

Las mujeres romanas aparecen en Salustio generalmente en contextos de guerra civil o extranjera, como víctimas de la misma, en papeles y actitudes dramáticas. A ese respecto es muy reseñable el siguiente párrafo, referido a los rumores en Roma sobre la guerra civil contra Catilina y los suyos:

«Con estos acontecimientos andaba la ciudad sobresaltada y alterado su aspecto. Tras la suma alegría y regocijo que había engrendrado la prolongada paz, a todos invadió de repente la tristeza. [...] Encima, las mujeres, a las que les había entrado un temor, el de la guerra, al que, en razón de la potencia del Estado, no estaban acostumbradas, se daban golpes, tendían al cielo sus manos suplicantes, compadecían a sus hijos pequeños, no paraban de hacer preguntas, se asustaban con cualquier rumor, se arrancaban todo y, olvidándose del fasto y los placeres, desconfiaban de su suerte y de la de la patria» (Cat. 31.1-3)

Este texto de Salustio describe muy bien, casi de manera teatral, el pavor de las romanas ante las posibles consecuencias de la guerra que se avecinaba. Algunos elementos son destacables en el texto: el temor, los golpes, las manos suplicantes, los hijos pequeños, los rumores, el olvido del placer y la desconfianza en el futuro. En otros textos aparecen estos mismos elementos. Así, Julio César, en su discurso ante el Senado, enumera los males de la guerra:

«(Otros) Han enumerado el salvajismo de la guerra, las desgracias que acaecen a los vencidos: muchachas y niños raptados, hijos arrancados del abrazo de sus padres madres de familia sufriendo los caprichos de los vencedores, templos y casas saqueados, muertes e incendios provocados, en fin, todo repleto de armas, cadáveres, sangre y pesar» $(\text { Cat. 51.9 })^{26}$.

Lógicamente, Salustio, como cesariano que era, no podía sugerir que esta creencia de César, puesta en sus labios en el año 63 a.C., estuviera en contradicción con su actuación en el año 49 a.C., cuando su entrada en Roma. Por eso, en una de las epístolas dirigidas al dictador, le espeta:

${ }_{25}$ Quis rebus permota ciuitas atque immutata urbis facies erat. Ex summa laetitia atque lasciuia, quae diuturna quies pepererat, repente omnis tristitia inuasit. [...] Ad hoc mulieres, quibus rei publicae magnitudine belli timor insolitus incesserat, adflictare sese, manus supplices ad caelum tendere, miserari paruos liberos, rogitare omnia, <omni rumore> pauere, <adripere omnia > superbia atque deliciis omissis, sibi patriaque diffidere.

${ }^{26}$ Plerique eorum, qui ante me sententias dixerunt, conposite atque magnifice casum rei publicae miserati sunt. Quae belli saeuitia esset, quae uictis adciderent, enumerauere: rapi uirgines, pueros; diuelli liberos a parentum conplexu; matres familiarum pati quae uictoribus conlubuissent; fana atque domos spoliari; caedem, incendia fieri; postremo armis, cadaueribus, cruore atque luctu omnia conpleri. 
«¡Ay, cuán brutales y crueles eran antes de la victoria que tú has logrado aquellas muertes secretas y repentinos asesinatos de ciudadanos, aquella huida de mujeres y niños a refugiarse con padres e hijos, el saqueo de las casas!» $\left(\right.$ Ep . 1.4.2) ${ }^{27}$.

Esas mismas consecuencias de la guerra civil que César no deseaba, sí lo hacían sus enemigos, según el parecer de Salustio en otra de sus epístolas:

«Ni los hijos huérfanos, ni los padres de avanzada edad, ni el dolor y gemidos de hombres y mujeres han hecho doblegar el bárbaro espíritu de esos sujetos (Catón, Domicio y otros enemigos de César) para que dejen de hacer mal y calumniar cada día con más crueldad, y de privar a los unos de su categoría, a los otros de su ciudadanía» (Ep. 2.4.2)

Desde luego, las consecuencias de las guerras civiles no eran algo nuevo propio de la época de César. Ya en la era post-silana, el excónsul Filipo advertía en un discurso a los senadores optimates de las consecuencias del levantamiento de Emilio Lépido:

«Pero si estos consejos (de Lépido) os placen, si tal es el abatimiento de vuestro ánimo que se os olvidan los crímenes de Cinna, cuya vuelta a nuestra ciudad acabó con lo más florido de nuestro orden, y queréis entregaros con vuestras esposas e hijos a Lépido, ¿qué necesidad tenéis de decretos, qué del auxilio de Catulo?» (Hist. 1.77.19) ${ }^{29}$.

Estos sufrimientos de las mujeres (y de los niños y los ancianos) en las guerras civiles incluían, al parecer, raptos de niños, mujeres violadas, casas saqueadas y destruídas, muertes y asesinatos. Curiosamente, el párrafo donde más crudamente se describen estos actos no hace referencia a un conflicto civil, sino a uno servil, a los actos acaecidos por los espartaquíadas en Foranio, localidad lucana:

«[...] entrando secretamente en Foranio, sin la más mínima sospecha de los habitantes del lugar. Y, enseguida, los fugitivos, en contra de las órdenes de sus jefes, comenzaron a violar a las jóvenes y a las viejas, y otros $<\ldots>$ hacían burla de los que aún vivían, les hurgaban en sus heridas de un modo atroz, sin cuidarse tampoco de los que agonizaban con el cuerpo mutilado. Otros aplicaban fuego a las casas, y muchos esclavos de aquel lugar, aliados de los invasores en virtud de su índole servil, sacaban fuera de sus escondrijos los tesoros de sus señores, y a los señores mismos: nada, en suma, parecía inviolable o sacrílego al furor y a la bajeza servil de aquellos bárbaros» (Hist. 3.98.2-3) ${ }^{30}$.

27 Eheu quam illa occulta ciuium funera et repentinae caedes, in parentum aut liberorum sinum fuga mulierum et puerorum, uastatio domuum ante partam a te uictoriam saeua atque crudelia erant!

28 Non orbi liberi, non parentes exacta aetate, non luctus gemitus uirorum mulierum immanem eorum animum inflexit, quein acerbius in dies male faciundo ac dicundo dignitate alios alios ciuitate euersum irent.

${ }^{29}$ Haec si placent, si tanta torpedo animos obrepsit, ut obliti scelerum Cinnae, ciuis in urbem reditu decus ordinis huius interiit, nihilo minus uos atque coninges et liberos Lepido permissuri sitis, quid opus decretis, quid auxilio Catuli?

${ }^{30}$ [...] peruenit ad Anni forum ignaris cultoribus. Ac statis fugitiui co $<n>$ tra praeceptum ducis rapere ad stuprum uirg $<i>$ nes matr $<$ ona $>$ sque et alii $[\ldots]<n>$ unc restantes et eludebant, simul nefandum in modum peruerso uolnere, et interdum lacerum corpus semianimum omittentes; alii in tecta 
Parece claro que Salustio utiliza a las mujeres romanas anónimas casi siempre como víctimas de las guerras, a las que el historiador se opone por sus violencias y destrucciones. Las mujeres, en todos estos textos, aparecen como personajes dramáticos de tragedia griega: temerosas, asustadas, con los hijos a cuestas, siendo objetos de raptos, violaciones, muertes. Estas citas aportan, pues, poco al estudio histórico, son notas de color (incluso de sabor), y dicen poco de la opinión salustiana de sus compatriotas femeninas, que aparecen indefensas y con poco sentido del comedimiento y el autocontrol. Un pensamiento habitual entonces e incluso ahora.

Me parece interesante contrastar el uso de la mención de mujeres extranjeras comparándola con el de las mujeres romanas. Hay que diferenciar, como en otros historiadores, la imagen positiva de las mujeres extranjeras occidentales de la de las orientales. La única mención a orientales, Cat. 7.4, es para achacar a los burdeles de Asia el comienzo de la decadencia moral de los soldados romanos. Sin embargo, las extranjeras occidentales, númidas, galas e hispanas que aparecen en Salustio, en un total de 6 menciones, no aparecen ni como temerosas ni como víctimas de las guerras. Solo en una mención (Jug. 94.5), las númidas huyen ante un combate con sus hijos; y en otra, aparecen más como víctimas de la poligamia que como temerosas o pusilánimes (Jug. 80.6-7). En el resto de menciones, las mujeres extranjeras son aguerridas y valientes, incluso arrojadas. Las númidas participan en el combate junto a sus hijos arrojando piedras (Jug. 67.1); las galas del ejército de Espartaco salen al monte, probablemente en algún tipo de ritual mágico, para que no les viniese la menstruación la víspera de un combate (Hist. 4.40) $)^{31}$; las hispanas son elegidas para el matrimonio según su valentía y arrojo en el combate (Hist. 2.91). En otro fragmento, Salustio nos relata el hecho de que en una localidad del norte, Meóriga, cerca de Clunia, fueron las hispanas las que se negaron a que los hombres se rindieran a Pompeyo en el año 75:

«Las madres recordaban los actos de valor de sus padres a los soldados que se preparaban a partir para una guerra o una correría de saqueo, cantándoles sus gestas. Así, sabido ya que Pompeyo marchaba a la cabeza de un ejército hostil, los más ancianos propusieron la paz y la sumisión; las mujeres se negaron taxativamente a su decisión y se separaron de los hombres empuñando las armas. Se parapetaron en un lugar bien abastecido cerca de Meóriga y se proclamaron carentes de patria, de padres y de libertad, renunciando a amamantar, a parir y a otras funciones propias de las mujeres. La juventud, inflamada por estos sucesos, revocó los decretos de los ancianos» (Hist. $2.92)^{32}$.

iaciebant ignis multique ex loco serui, quos ingenium socios dabat, abdita a dominis aut ipsos trahebant ex occulto; neque sanctum aut nefandum quicquam fuit irae barbarorum et seruili ingenio.

${ }^{31}$ Es la interpretación que defiendo en J. L. Posadas, Gayo Salustio Crispo..., citado, pág. 187. Me coloco, pues, en contra de la de A. ERnout, «Salluste, Histoires IV, 40», RPh 49, 1925, pp. 55-59, que, basándose en Lucrecio 6.794-796, pensó que este fragmento aludía a una costumbre de las mujeres galas de evitar el contacto con otras personas durante su menstruación, debido a lo desagradable de la misma. Lo cierto es que el contexto del fragmento es la inminencia de un combate: es sabido que las espartaquíadas tomaban parte de las batallas, por lo que es posible que algunas mujeres prefirieran retrasar su menstruación para no incomodarlas durante momentos tan críticos.

$32<$ A matribus parentum facino $>$ ra militaria uiri $<$ s memora $>$ bantur in bellum $a<u$ ad la $>$ trocinia pergent $<$ ibus, qui il $>$ lorum fortia facta $<$ ca $>$ nebant. Eo postqua $<m$ Pom $>$ peius infenso exer $<$ citu $>$ 
En este fragmento, interesante a más no poder, son de destacar varios aspectos: las madres eran las que pedían a sus hijos que recordaran el valor de sus padres; el común de las mujeres se negaron a obedecer el consejo de los ancianos y, como los plebeyos del relato heroico de Roma, se separaron de los hombres, con las armas en la mano, y se parapetaron en un lugar (probablemente, un monte). Como los plebeyos de las secessiones, se proclamaron sin patria, sin padres y sin libertad y renunciaron a las "labores propias de su sexo": amamantar, parir. Fue el ejemplo de estas bravas mujeres lo que decidió a los jóvenes a seguir luchando. Lógicamente, este relato dramático, con las imágenes fuertemente asentadas en el colectivo romano de la secesión armada en el monte, y con la alusión, ya vista en relación a la menstruación de las galas, a la renuncia a las funciones propias de las mujeres, es más que positiva en Salustio: ¿se trata de un exemplum uirtutis que contraponer al de las mujeres romanas aterrorizadas ante el simple rumor de una guerra civil y de sus consecuencias consabidas de asesinatos, raptos y violaciones? Mi opinión es que sí, que Salustio empleó a las mujeres romanas como ejemplo de degradación moral, de vicio femenino y de cobardía, y a las mujeres extranjeras como ejemplo de virtud, de fortaleza y de valor. $\mathrm{Ni}$ una alusión a la impudicia en las menciones a extranjeras, ni siquiera entre las númidas, sometidas a la poligamia sin darse al adulterio, sino con resignación. Esto, más que nada, es muestra del sentimiento salustiano en favor de estas extranjeras o, más bien, en contra de las romanas de su época.

El resto de menciones a mujeres anónimas en Salustio va en este mismo sentido. Las mujeres adúlteras o las rameras que aparecen en sus obras son símbolos de degradación moral, no solo de ellas mismas, sino de los varones que las frecuentan: romanos presilanos (Cat. 7.4), catilinarios (Cat. 13.3, 24.3-4) y cesarianos inmoderados en la victoria (Ep. 1.4 .4 y 1.8 .2$)$.

\section{Conclusiones}

El estudio prosopo-historiográfico, ya defendido en otros trabajos, arroja interesantes conclusiones si se aplica de manera exhaustiva a las mujeres en Salustio. El historiador, cesariano y (en mi opinión) antoniano, presenta a las mujeres de tal manera que proporciona visos de realidad histórica siempre y cuando se le despoje de evidentes (y no tanto) intencionalidades morales o políticas. El retrato que, de algunas de las protagonistas de la conjuración de Catilina, nos ofrece Salustio es complejo y difícil de interpretar. En general, y pese a ser algunas de ellas ejemplos de actuación en favor de la República y en contra de Catilina, estas mujeres son criticadas por Salustio casi siempre con rasgos morales referentes a su impudicia. Otras menciones a romanas aparecen en contextos de temor a ser víctimas de las guerras civiles o las proscripciones: ante las dificultades, Salustio presenta a las romanas como timoratas,

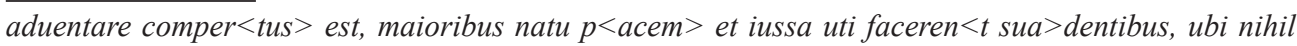
$a b<n u>$ endo proficiunt, se $<$ para $>$ tae a uiris arma cep $<$ ere et $>$ occupato prope Meo $<$ rigam $>$ quam tutissimo loc $<$ o ill $>$ os testabantur ino $<$ pes pa $>$ triae parientumque $<e t>$ libertatis, eoque uber $<a>$, partus et cetera mul<ierum $>$ munia uiris mane $<$ re $>$. Quis rebus accensa iu $<$ uen $>$ tus decreta senio $<$ rum aspernata $>$. Como F. Pasoli, acojo aquí el $<q u i$ il $>$ lorum de Hauler frente al $<u b i$ il $>$ lorum de Maurenbrecher. 
asustadizas, incluso en escenas dramáticas de falta de autocontrol. Frente a ellas, el ejemplo conmovedor de arrojo, valentía y fiereza de las extranjeras "occidentales" (númidas, hispanas y galas).

El cuadro general que nos presenta Salustio es el de una Roma sumida en el adulterio y la impudicia, con algunas mujeres participando en política y con el común de las romanas sometidas al arbitrio de los vencedores en las guerras, sin oponerse a ellas, como plumas al viento de la historia. Solo encuentra Salustio ejemplos de virtud y de valor en las extranjeras. Una actitud pesimista, moralista y anticuada que habría de calar en sus lectores y en sus seguidores (como Tácito). A pesar de eso, si despojamos a Salustio de sus intencionalidades moralistas o políticas ${ }^{33}$, podemos utilizar sus menciones a mujeres como elemento de conocimiento histórico para comprender la actuación de algunas de ellas a lo largo del último siglo de la república romana.

${ }^{33} \mathrm{Y}$, por tanto, huimos de las simplistas descripciones de decadencia moral, divorcios y emancipación femenina (para mal) de Carcopino y sus seguidores. 